\title{
Social Informatics: Natural Tools for Students' Information Training in The Conditions of Embodied and Mental Approaches Being Employed
}

\author{
Daria Barkhatova $^{1}$, Elmira Nigmatulina ${ }^{2}$, Tatyana Stepanova ${ }^{3}$
}

\begin{abstract}
The relevance of the problem under study is due to the society's requirements for the quality information training of a personality which is oriented to forming the solid fundamental knowledge as well as to developing the cognitive capacities that are needed for solving mental tasks. With regard to this, the paper is aimed at finding out the opportunities of applying the natural tools in information training of students from the standpoints of embodied and mental approaches. The main idea of these is integrated studying of an object, beginning with learning it in an "embodied" way and finishing with abstract models formed in the human memory. The leading approach to the research is the integrated one taking into account the psychological and pedagogical, didactic and methodological constituents. It allows identifying the psychological and pedagogical conditions of application of natural tools as well as the possible ways of their use. The authors describe models of natural tools of computer science training in individual sections of the school course as the main results. The materials of the paper are of practical value in methods of teaching computer science to students at various stages of education.
\end{abstract}

Keywords: embodied approach, mental approach, information training, natural training tool, tool use in education.

\section{Introduction}

The modern world is currently characterized by a quick tempo of life, a global, rapid and continuous nature of processes occurring in it. Alongside with it, the habitual pattern of human life changes requiring from man yet new abilities and knowledge, an ability to easily fit in new conditions, speedy mobilization and activation of information resources for solving a number of professional and daily tasks. Mental work takes over from manual work. Now, information gains a special value as a universal category of social development and as an indicator of quality of life (Tarman, 2016).

These processes have necessitated the change of educational paradigm in the area of information training of a personality which is oriented to forming the fundamental knowledge and abilities that are needed for human information activity. The emergence of an individual direction of research in computer

${ }^{1}$ Assoc. Prof., Candidate of Pedagogy, Krasnoyarsk State Pedagogical University named after V.P. Astafyev, darry@mail.ru

${ }^{2} \mathrm{PhD}$ Student, Head of the Department Office, Krasnoyarsk State Pedagogical University named after V.P. Astafyev, nigmira@ yandex.ru

${ }^{3}$ Assoc. Prof., Candidate of Pedagogy, Krasnoyarsk State Pedagogical University named after V.P. Astafyev, step1350@mail.ru 
science was quite an expectable response of science to this need. It was created in Russia in the mid1980s and got the name of social informatics (Kolin, 2015). Today, this is a compulsory section of the school computer science course which is aimed at the development of information worldview in students as well as qualities that they need for acting efficiently in an information environment.

All over the world computer science teacher now faces an important task to select the methods and tools that are up to the demands of time and requirements of the educational system (Mathews, 2016, Korkmaz \& Avci, 2016). Here it is the integrated approach that is important, as it takes into account the psychological and pedagogical, didactic, and methodological constituents that ensure the formation of solid knowledge and abilities for cognitive information processing. The natural training tools can become such means as well as an important supplement for the educational process with the study information to be perceived.

The objective of the paper consists in describing the psychological and pedagogical foundations and ways of applying the natural tools in students' information training from the standpoint of embodied and mental approaches.

\section{Literature Review}

The starting point when the school computer science course, or informatics, was launched can be considered the year of 1985, as the "Fundamentals of informatics and computer science" course was introduced. The educational paradigm which was characteristic for the time span had the principal objective of the universal computer literacy. That was understood as fundamentals of algorithmics and programming taught to everyone (Makarova et al., 2014, p. 150). Ershov (1981) pointed out that the main task of the course is not so much teaching the practical skills of programs writing and PC working practices rather than forming in all students the operational and combinatorial thinking, an ability for abstracting, reasoning and acting. Meanwhile, the "fusion" of operational knowledge and algorithmic thinking act in a profound relation with other components of education (Ershov, 1981).

The development of computer science and emergence of operating systems with graphic user interface and new kinds of software led the pedagogical community to realize the necessity of changing the computer science teaching paradigm. Beginning with 1999, the objective of the study course has been expanded considerably, with forming the schoolchildren's information culture becoming the reference point. It is forming the abilities and skills of using the modern technical information and communication technology means in one's activity that becomes the main idea of the school IT course (Makarova et al., 2014, p. 151). However, as the volume of 
information grew, new information technologies developed, and the quantity of people involved into the information sphere of activity increased, a rethinking of the content and methods of training was required from education. The processes of IT penetration and the human activity globalization rendered the necessity to introduce a new domain of knowledge - social informatics - relevant.

Social informatics is a science studying the complex of problems associated with information processes taking place in the society. This is a new trend in science that has emerged at the junction of such areas as IT, sociology, psychology and philosophy (Starikov, 2012, p. 264).

In Russia, it was founded by A.D. Ursul (1990). He highlighted the influence of information processes in the society on the content and methods of informatics from the philosophical point of view. Being a social process in its essence, IT penetration has to have a humanist focus, with its means acting merely as a tool for acquiring the information and basis for social, scientific and technical advancement. Alongside with that, A.D. Ursul pointed out the negative consequences of IT penetration that required urgent measures (Kolin, 2011, p. 460).

Social informatics has been rapidly developing in Russia for over 25 years already. Currently this is one of the principal sections of IT which is a scientific basis for forming the information society as well as for studying the new opportunities and new problems of people under the rise of a completely new information environment of their life and professional activity (Kolin, 2015). The main task of social informatics is to form the ability to find one's bearings correctly in the new information reality both at the world level as a whole and in Russia. It also involves forming the idea about computer literacy being a must without which one is left out of the modern information environment. Social informatics deals with methodological preparation for further studying and mastering the information technologies of the relevant domain, the future professional activity, and life activity as a whole, as well as for participating in development of these technologies (Starikov, 2012, p. 265). In order to solve the tasks, the students' information training at IT lessons is quite essential. The training relies on forming of a personality's information culture, developing its information potential, i.e. its having the knowledge and skills, creative abilities, cultural particularities and unconscious motives (Osipova-Derbas, 2008, p. 229), as well as its intellectual potential, i.e., its ability to produce and absorb new knowledge (Kolin, 2011, p. 462). 
Having to form new qualities has directly influenced the computer science teaching methods as well. Unlike the Soviet times, as the word-based methods and programmed training methods prevailed that were formed from the viewpoint of cybernetics (Sofronova, 2004, p. 38), the modern time is characterized by mostly systemic and activity-based approach. This approach is designed in such a way as to ensure forming the readiness for self-development and continuous education, designing and constructing the social environment of development for learners within the education system, their active academic and cognitive performance, and building the educational process with individual age-related, psychological and physiological particularities of learners borne in mind (Makarova et al., 2014, p.153).

As forming the knowledge, abilities and skills was abandoned for practice-oriented abilities one needs for life and activity in an information society, the very tools of training changed. They now are up to the requirements of integrated studying of a subject and they boost the students' cognitive activity within the activity-based context. Among such tools, there are natural training ones.

At present, there are various approaches to teaching the school IT and ICT course using the natural training tools. However, such tools tend to be applied in the section of modeling and formalizing as tools for natural experiments (Andujar et al., 2013) or in the section "Structure of a PC" as the visual aids. There is no doubt that the conventional visual aids are needed in teaching computer science, which is determined by their specific functions which it is either impossible to vest in the PC or inexpedient from the psychological and pedagogical viewpoint or the content-related one. However, alongside with the demonstration materials, a lesson on computer science has to employ such training means as to plunge the students into the methods or phenomena being learned via encouraging their cognitive activity.

Studies are currently conducted of the role of natural tools in teaching the algorithmics and programming line (Stepanova, 2014), the use of robotic engineering (Maris \& Boekhorst, 1996, Barkhatova, 2015) and electronic design kits at the IT lessons (Romero et al., 2009). The research relies on embodied (Varela et al., 1993, Wilson, 2002, Alyushin \& Knyazeva, 2009, Shapiro, 2011) and mental approaches in education (Cartelli, 2009, Lebedeva et al., 2015, Bazhenova et al., 2016).

The embodied approach is based on a radically new theory of embodied cognition. According to it, brain is not the only resource available to people for solving problems. It is the 
human body and perception that act as a guide in the outer world replacing the complicated mental operations by sensual ones (Wilson \& Golonka, 2013, p. 625).

At present, many scientists and researchers mention the deficiency of reducing the cognition process to a model of mental manipulation with symbols. They emphasize the importance of communication of mind and body in the process. Cognition is a complicated versatile process that can go far beyond the framework of mind. In it, using special tools - body included - allows one to solve a number of problems and tasks one faces (Rambusch \& Ziemke, 2005, p. 1805).

If the body is involved in the process of studying of any subject, this allows activating the students' cognitive processes, rendering the cognition more profound, and studying the processes and phenomena at the level of a profound and complete understanding owing to manipulating the objects "live" (Kukhtina et al., 2015, Stepanova, 2014, Nigmatulina \& Pak, 2017). However, in order to ensure the entire cycle of knowledge acquisition, it is not sufficient to involve the embodied cognition methods only. The information received has to be consolidated in the human memory thus ensuring the transition from the certain to the abstract. Such transition can be built on the basis of the mental approach.

The mental approach allows learning to be viewed as a process of formation and development of human mental schemes during the person's information interaction with the environment (Lebedeva et al., 2015).

A mental scheme is a set of notions and associations between them that are used by people for interpreting the processes and phenomena under consideration without turning to scientific and disciplinary knowledge (Cartelli, 2009, p. 193). As the time passes, the modelrelated ideas undergo transformations towards generalization and abstracting and they form the language. The formed mental schemes determine an individual's knowledge and allow the individual to perform thinking (Bazhenova et al., 2016). The total of mental schemes makes up the structure of one's thesaurus.

These fundamentals of the mental approach determine the rules for studying any domain: first, the formation of sensual mental schemes of a domain with the help of their mental models has to be ensured, and then all images, models and notions have to be systemized using the linguistic means (Fig. 1) (Nigmatulina \& Pak, 2017). 


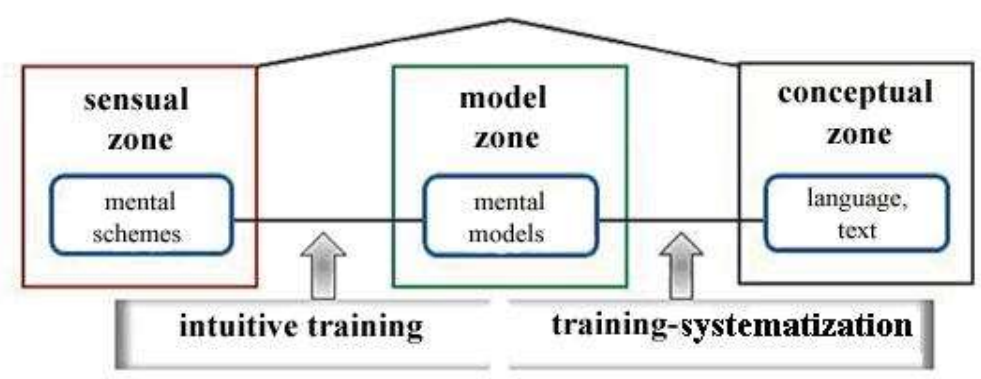

Figure 1. Learning a subject from the standpoint of embodied and mental approaches.

Note: The following figure and note are each adapted from Nigmatulina \& Pak (2017, p. 10).

In studying computer science, the embodied cognition methods allow forming the mental schemes in the sensual area while the mental didactics ones allow ensuring the transition from the certain to the abstract, from action to notion (Bazhenova et al., 2016). Such an approach will ensure the staged formation of information and intellectual potential of a personality based on the solid knowledge and the developed algorithmic and abstract thinking.

Thus, given the society's requirements for the new information training of a personality that is oriented to one's ability to act efficiently and safely in conditions of the global information society, the methods of embodied and mental approaches will allow ensuring the development of the personality's information and intellectual capacity. The use of natural tools within this context will eliminate the passive role of students at IT lessons. It is the active inclusion of students into the cognitive process that is the main objective of using such tools.

\section{Methodological Framework}

The objective of the research consists in developing and exploring the opportunities of a natural tools kit in the students' information training in conditions of embodied and mental approaches being employed.

Tasks of the research:

1. Analysis of the Russian and foreign experience of using the natural computer science teaching tools.

2. Analysis of psychological and pedagogical, didactic and methodological constituents of the school computer science course and finding out the opportunities of natural training tools in the process of formation of new knowledge and diagnostics of understanding. 
3. Description of a model of natural tools for teaching computer science in individual sections of the course and the possible pedagogical effect of using them.

The theoretical analysis of psychological and pedagogical, methodological literature on the topic of the research is conducted, its results are generalized; the natural training tools are modeled and the pedagogical effect of using them is forecast.

The research relies on an integrated approach to enhancing the quality of information training owing to the application of ready natural tools in teaching computer science as well as to creation of the tools by the very students' own forces using the state-of-the-art technologies. The embodied and mental approaches to designing the didactic principles of developing the algorithmic, logical and abstract thinking in students are used, and their cognitive, exploratory capacities, and the fundamental knowledge on information activity are formed and developed.

\section{Results and Discussion}

Psychological and pedagogical foundations of using the natural tools in teaching computer science

Having to build the process of teaching computer science at school on the standpoint of mental and embodied approaches is due to the age-specific particularities of the students' cognitive capacities as well as individual needs of the ways of perception and acquisition of the material selected in line with their knowledge level.

While analyzing the age-related particularities of schoolchildren's cognitive capacities at different educational stages (see Table 1), it can be stated that all schoolchildren of various age highly need visual aids (Fridman, 1984, Muhina, 2006). However, if mainly ready-made visual aids have to be used at primary school, the secondary grades should opt for the ones that are designed and crafted by students themselves. L. Fridman points out that schoolchildren have to be taught how to analyze the visual aids used, to find out their essential properties and particularities in order to overcome the passive and superficial character of perception that many adolescents have. At the stage of the senior school age, rather complex visual aids can and must be used, possibly involving the very students into the process of designing and building the aids (Fridman, 1984).

Table 1

Characteristics of the Students' Cognitive Capacities

\section{Age groups Particularities of cognitive capacities}




\begin{tabular}{|c|c|}
\hline $\begin{array}{l}\text { Primary } \\
\text { school age } \\
\text { (from 6-7 up } \\
\text { to } 9-11 \text { years } \\
\text { old) }\end{array}$ & $\begin{array}{l}\text { The motivation of cognitive activity is poorly developed. Attention is hard to be kept for a long } \\
\text { time. It is difficult to learn a large volume of material. Playing and productive activity kinds } \\
\text { take the principal place in learning. There is an aspiration to solve a task independently, to do a } \\
\text { certain experiment. There are high requirements for the ready-made visual aids (including ones } \\
\text { used as a means for boosting attention). }\end{array}$ \\
\hline $\begin{array}{l}\text { Secondary } \\
\text { school age } \\
\text { (from } 11-12 \\
\text { up to } 15 \text { years } \\
\text { old) }\end{array}$ & $\begin{array}{l}\text { There is an interest in independent activity where the teacher is an assistant. The perception } \\
\text { processes get intellectualized. There is an urge to single out the main and the secondary and one } \\
\text { for structured information. Analyzing the content of the material, the logics of its structure, } \\
\text { singling out the essential points ensure the maximum efficiency of reproduction. There is a need } \\
\text { of making visual aids by oneself. Some adolescents keep high requirements for the ready-made } \\
\text { visual aids. }\end{array}$ \\
\hline $\begin{array}{l}\text { Senior school } \\
\text { age }(15-18 \\
\text { years old })\end{array}$ & $\begin{array}{l}\text { All mental processes are consolidated and improved, with their motivation gaining a high level. } \\
\text { Reflection nature of thinking and self-cognition develop rapidly. Quite complex visual aids can } \\
\text { and must be used, with the very students possibly involved into the process of designing and } \\
\text { constructing the aids. }\end{array}$ \\
\hline
\end{tabular}

Note. The authors' analysis is based on the works by Fridman (1984) and Muhina (2006).

Another important feature is the students' need of dynamic independent activity that allows boosting their mental processes to the full. At any age, self-fulfillment, demonstration of one's capacities and knowledge are important for students and so is the appraisal by peers and teachers.

The natural tools of training allow implementing the principles of illustrative, conscious and active character to the full extent, acting on the one hand as a visual material and on the other hand as a tool for studying a subject via activity. Moreover, they can be used not only as ready-made didactic tools but also as an educational result which renders material the knowledge obtained. Having studied the material, the students can create their own natural tools themselves, which allows systemizing the knowledge and making the abstract notions more definite.

The next important point in the implementation of embodied and mental approaches in teaching computer science is having to take into account the information perception channels.

Among the first scientists to speak about the dependence between perception type and learning success, there were psychologists - the founders of neurolinguistic programming, According to them, each individual while possessing all three perception modality actually uses at the maximum load only one of them - the leading one. However, this does not mean other perception channels cannot be used. In order to do this, the individual will need making additional effort that slows down the process of acquisition of the study information. During learning, this can result in gapped knowledge and abilities, which once again emphasizes the importance and significance of matching the perception modality correctly when teaching various school subjects (Grinder, 1991, Bandler \& Grinder, 1975). 
There is a number of differences between kinesthetic, visual and auditory learners. They touch on a very broad range of things, e.g. the way thinking, memory, training methods are organized. Undoubtedly, this has to be reflected in selecting the teaching methods for this or that section of computer science.

The analysis of literature and of teachers' and researchers' experience on the problems of teaching the computer science course (Lapchik et al., 2008, Vitkute-Adzgauskiene \& Vidziunas, 2012, Lebedeva et al., 2015) has shown that the teachers use practice-oriented tasks, writing program code accompanied by detailed comments, computer presentations, diagrams and mental maps ensuring a varying degree of visualization of the study material etc. as means and techniques helping to enhance the efficiency of learning the computer science course and to facilitate the perception of abstract study information. However, all these training means are mostly aimed at visual and auditory learners as it is to these channels that they address. Nevertheless, statistics shows (Vopneruk et al., 2005, Plighin \& Gerasimov, 1996), that it is the kinesthetic perception channels that are dominant in 30-40\% of people. They feel the world around them and perceive the greater part of information sensually, via the sense of touch and smell, associations and actions performed. Kinesthetic learners need activity in order to understand finally - to make something with their own hands and to experience by touch (Stepanova, 2014, p. 52). This is why completely new training tools are essential that would be targeted at kinesthetic channels of perception and at activating the motor area of memory.

It is believed that the information training process will ensure the formation and development of the required qualities in students if the system of learning is constructed using the natural tools - ones that are targeted at activating the motor area of memory (alongside with the visual, auditory and abstract ones).

Therefore, the natural tools of teaching the computer science will be an important supplement to the educational process that is oriented to conscious understanding of the information perceived, to forming the solid knowledge, and to developing the students' thinking in a versatile way. Such tools will allow them to reveal the essence of the notions and phenomena under study, to inquire into algorithms at a tactile level, to look at the object under study from various standpoints etc. and subsequently, based on the actions identified, to construct an algorithm, to create an information model or to perform another abstract action. Models of natural computer science teaching tools 
The studies in application of natural tools in teaching computer science are conducted at the basic chair of computer science and information technologies in education of the Institute of mathematics, physics and computer science, Krasnoyarsk State Pedagogical University named after V.P. Astafyev. There are several directions of work:

- development of natural tools for teaching the school computer science course, technique of using them;

- training of further IT teachers in implementing the embodied and mental approaches at computer science lessons;

- organization of distance learning using the natural training tools.

As of today, there is a number of natural tools developed in the area of information training of schoolchildren:

1) "Theoretical fundamentals of computer science":

- Calculating frame for working in various systems of notation;

- Visual sets showing selection of elements with various operations on sets.

2) "Fundamentals of programming":

- Simulators of implementation of algorithms using the simple types of data;

- Simulators of implementation of algorithms using arrays and strings.

The tools allow building the training process from the easy to the difficult and from single operations to multiple ones, from real objects to abstract ones.

So, for example, when studying the "Systems of notation" topic, the calculating frame can be used. With them, first, the basic notions of counting and quantity are discussed, the number digit positioning processes are visualized, and the algorithm of transiting from one notation system to another one is inquired into "manually". Only after that, the symbol recording is studied (Fig. 2). 


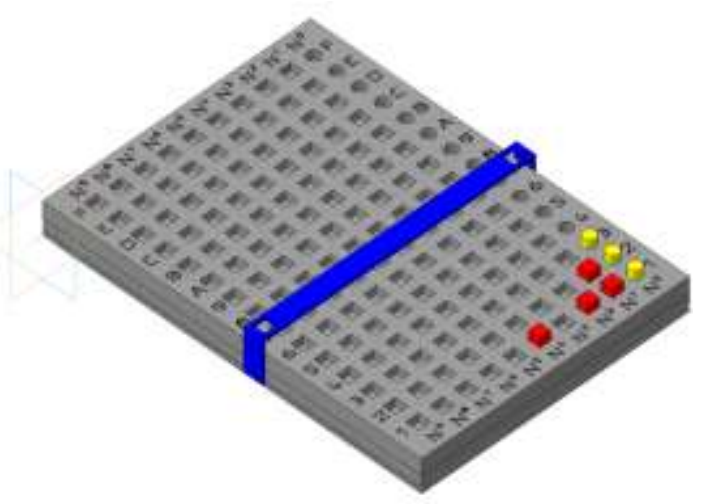

Figure 2. Various notation systems calculating frame.

The calculating frame is a board with cells in which beads are placed in turns, working from the rightmost bottom cell upwards. There is a slider to mark the notation system with which the learner is currently working. Once a column-digit is filled up, all beads are removed from the column and replaced by one bead to be put into a higher order digit. It is proceeded this way until the suggested quantity of beads runs out. The process allows demonstrating the algorithm of a number passing to the next digit and explains the meaning of position notation systems. Similarly, the reverse procedure is possible when there are already beads laid out in the cells.

For studying the "Classes and attributes of objects" topic, the kit was developed that consists of objects with various attributes (cubes and balls of different color and size) as well as shapes for sorting the objects into classes. The students are asked to subdivide the objects into shapes according to various attributes, with the mutually excluding ones not used as well. The process illustrates the notions of logical operations on sets.

Moreover, simulators that allow visually inquiring into the work of algorithms with simple and compound data types have been developed.

The main idea behind creation of a simulator for working with simple data types was to show the necessity of describing the variables and data types as well as the ways of recording them in the computer memory while the program is executed. The simulator is a board with cells of different size but similar ones for one and the same type. For example, cells for storing the real data type exceed the integer data type twice and they have a separator for storing the integer and fractional parts. The certain values operated by the algorithm are written down in special beads the size of which matches the memory cells of the relevant value. 
When inquiring into the algorithm, the students replace the data beads from one cell to another according to the program code. Meanwhile, an integer data shape bead can be placed into a real data cell but not vice versa.

When studying the complex data types, the students often have such problems as losing the distinction between an element's index and its very value, exceeding the limits of a data string, failure to understand the process of ordered reading of elements etc. It appears efficient to use the kinesthetic simulators in training for solving such problems. They will allow the students to "manually" record an array element by element, to bubble sort it, to locate the required element etc.

The natural tool for studying statistical one-dimensional arrays is a board with cells and a slider to limit the array dimensionality (Fig. 3).

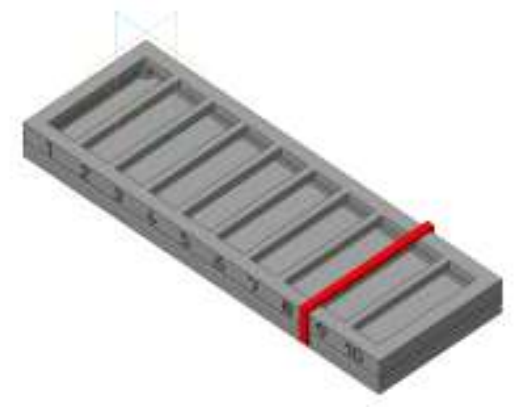

Figure 3. Simulator for manipulating one-dimensional arrays.

Before the work is started, a student has to decide on the array dimensionality, next - on the data type, as the array is a set of the same-type components. For emphasizing the same-type character of the data, data of one type are marked on beads of the same shape (round or square). Then, the created array has to be filled with elements. Filling is performed in cycles from 1 to N, where teacher is the counter.

Students may have certain difficulties studying the algorithms of array sorting and element searching.

An example of natural tool for studying the sorting algorithms can be a set of balls placed in cells (Fig. 4). 


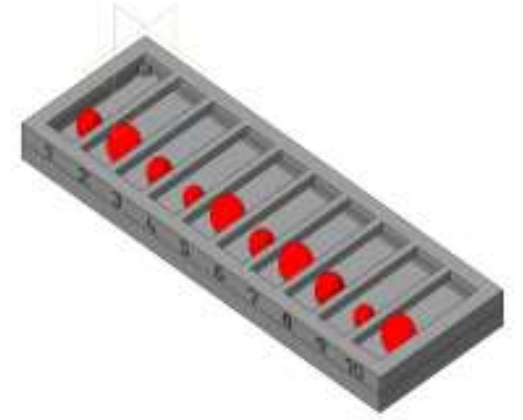

Figure 4. Studying the algorithms of one-dimensional arrays processing.

Each cell is numbered - marked with the array element index, and balls are of various sizes, which illustrates their different values.

The bubble sorting of the array is simulated according to the following rules: only one ball may be picked up and it may be compared with the neighboring ball only. If the next ball is larger, one has to swap them. However, here a problem arises: how one can swap the balls if only one ball may be picked up. While solving the problem, the necessity of using an additional variable can be demonstrated.

The practice of using the model confirms that once an algorithm is performed manually, the text of the program executing the algorithm becomes clear to each and every student.

Such a simulator can also be used for visualizing the more complicated sorting algorithms - Hoare sorting, bit or digit sorting - that frequently fail to be understood even by more advanced students after the first explanation, using words only.

The next example is the task of finding the minimum/maximum value of elements of a sequence.

Using the same simulator presented above in Fig. 4 and a flexible tape, the first ball is measured. This one is considered to be a reference of the smallest ball. Next, the reference ball is compared to the following balls. Once a new ball is smaller than the reference one, the new size is taken with the flexible tape.

Similarly, the largest ball or the ball of a said size can be found.

All the described tools have been created using the 3D-prototyping technology with a 3Dprinter. Students and teachers of the chair of computer science and information technologies in education of V.P. Astafyev CSPU took part in preparation and printing of the objects. 
Further work within this project consists in elaborating the kit of natural tools for teaching computer science and in conducting an experiment of their testing out among schoolchildren of grades 3-4, 8-9 and 10-11 at schools of Krasnoyarsk.

The kit can be copied and distributed within the system of students' information, engineering and technical training.

\section{Conclusion}

Changes in education associated with the society entering the age of information make it necessary to rethink the content of methods and tools for the students' information training from the standpoint of social aspects of human life.

The natural tools of teaching computer science are an important supplement to the educational process. They are oriented to conscious understanding of the information perceived, to forming the solid fundamental knowledge, and to developing the students' cognitive capacities that are essential for solving the mental tasks. The application of such tools proceeding from the mental and embodied approaches will allow transiting from the embodied cognition to forming the abstract mental images - mental schemes. And conversely, based on the formed knowledge and abilities the students can themselves create their natural objects visualizing their mental schemes. Thus, the toolkit can act both as a teaching aid and as a result - a product of students' creative activity.

Having to build the educational process on the standpoint of mental and embodied approaches is due to the age-specific particularities of the students' cognitive capacities as well as individual needs of the ways of perception and acquisition of the material selected in line with their knowledge level.

The natural tools of training will help to bridge the critical gap in the mechanism of computer science teaching to a large extent. They will eliminate the very cause of emergence of the gap while making the resulting system of knowledge more consistent and restoring the didactically correct structure of transition from sensory operating to abstract one.

\section{Acknowledgements}

The reported study was funded by Krasnoyarsk Region Science and Technology Support Fund according to the research project No. 2017031301651 "A set of natural-didactic training tools for Informatics and methods of their application". 


\section{References}

Alyushin, A.L. \& Knyazeva, E.N. (2009). Embodied approach in cognitive science. Philosophical Sciences, 2, 106-125.

Andujar, C., Schiaffonati, V., Schreiber, F.A., Tanca, L., Tedrek, M., van Hee, K. \& van Leeuwen, J. (2013). The Role and Relevance of Experimentation in Informatics. 8th European Computer Science Summit of Informatics Europe. URL: http://www.informaticseurope.org/images/documents/informatics-experimentation_2013.pdf

Bandler, R. \& Grinder, J. (1975). The Structure of Magic II: A Book About Communication and Change. Palo Alto, CA: Science \& Behavior Books.

Barkhatova, D.A. (2015). The use of devices with remote control at megalessons of informatics. Youth. Society. Modern science, technology and innovations, 14, 277-278.

Bazhenova, I. V., Babich, N. \& Pak, N.I. (2016). From projective and recursive technology of training to mental didactics. Krasnoyarsk: Siberian Federal University.

Cartelli, A. (2009). Between Tradition and Innovation in ICT and Teaching. In: Encyclopedia of Distance Learning, Hershey-New York: Information Science Reference, 187-193.

Ershov, A.P. (1981). Programming - the second literacy. URL: http://oberon2005.oberoncore.ru/classics/ae1981.pdf.

Fridman, L.M. (1984). Presentation and modeling in training. Moscow: Znanie.

Grinder, M. (1991). Righting the Educational Conveyor Belt. Portland, OR: Metamorphous Press.

Korkmaz, U. \& Avci, Z.Y. (2016). Turkish pre-service teachers' experiences with contemporary technology games and perceptions about teaching with instructional games. Research in Social Sciences and Technology, 1(1). URL: http://ressat.org/index.php/ressat/article/view/5

Kolin, K. (2011). Social informatics today and tomorrow: status, problems and prospects of development of complex lines in the field of science and education. TripleC, 9(2), 460-465.

Kolin, K. (2015). Social informatics: 25 years development of the Russian Scientific School. Strategic Priorities, 4(8), 51-63.

Kukhtina, E.S., Sorokin, A.V. \& Barkhatova, D.A. (2015). Thinking skills development with use natural tutorials at informatics lessons. Current Problems of Aviation and Astronautics, 2(11), 957-959. 
Lapchik, M.P., Semakin, I.G., Henner, E.K., Ragulina, M.I., Samylkina, N.N., Smolina, L.V., Udalov, S.R. (2008). Theory and methodology of training in informatics. Moscow. Academy.

Lebedeva, T.P., Pak, N.I. \& Rukosueva, N.V. (2015) About a training entity from the position of information and mental approach. Informatics and Education: Communication Borders, 7(15), 31-33.

Makarova, N.V., Nilova, Y.N. \& Titova, Y.F. (2014). Modern paradigm of teaching computer science on the basis of the new standard. Pedagogical Education in Russia, 1, 150-155.

Mathews, S.A. (2016). Using Digital Participatory Research to Foster Glocal Competence; Constructing Multimedia Projects as a Form of Global and Civic Citizenship. Journal of Social Studies Education Research, 7(2), 1-29.

Maris, M., \& te Boekhorst, R. (1996). Exploiting physical constraints: heap formation through behavioral error in a group of robots. In: Proceedings of IROS '96: IEEE/RSJ International Conference on Intelligent Robots and Systems, ed. M. Asada. Piscataway, NJ: IEEE Press, $1655-1660$.

Muhina, V.S. (2006). Age psychology. Development phenomenology. Moscow: Academy.

Nigmatulina, E.A. \& Pak, N.I. (2017). The student-centered training in programming in pedagogical university. Informatics and Education, 2(281), 8-14.

Osipova-Derbas, L. (2008). Forming of the informational potential of the personal and social system. Izvestia: Herzen University Journal of Humanities \& Science, 71, 228-234.

Plighin, A. \& Gerasimov, A. (1996). Research of regularities of development of representative systems of school students. Center of NLP in education. URL: https://www.nlpcenter.ru/index.php?sid=224\&did=1059

Rambusch, J. \& Ziemke, T. (2005). The Role of Embodiment in Situated Learning. In: Bara, B., Barsalou, L. \& Bucciarelli, M. (eds.). Proceeding of the 27th Annual Meeting of the Cognitive Science Society. Mahwah, NJ: Lawrence Erlbaum, 1803-1808. URL: http://csjarchive.cogsci.rpi.edu/proceedings/2005/docs/p1803.pdf

Romero, P., Boulay, B. D., Robertson, J., Good, J., \& Howland, K. (2009). Is Embodied Interaction Beneficial When Learning Programming? Lecture Notes in Computer Science Virtual and Mixed Reality, 97-105.

Shapiro, L. (2011). Embodied Cognition. New York: Routledge Press. 
Sofronova, N.V. (2004). Theory and Methodology of Informatics Training. Moscow. Higher school.

Starikov, S.A. (2011). About formation of social informatics. Herald of Chelyabinsk State Pedagogical University, 8, 122-131.

Starikov, S.A. (2012). Prerequisites of social informatics formation. Bulletin of OSU, 2(138), 264-267.

Stepanova, T. A. (2014). Theory of algorithmic thinking. Krasnoyask: Krasnoyarsk State Pedagogical University named after V.P. Astafyev.

Tarman, B. (2016). Innovation and education. Research in Social Sciences and Technology, 1(1). URL: http://ressat.org/index.php/ressat/article/view/3

Ursul, A.D. (1990). Informatization of Society: Introduction to Social Informatics. Moscow: Academy of Social Sciences.

Varela, F.J., Thompson, E. \& Rosch, E. (1993). The Embodied Mind: Cognitive Science and Human Experience. Cambridge: MA: MIT Press.

Vitkute-Adzgauskiene, D. \& Vidziunas, A. (2012). Problems in Choosing Tools and Methods for Teaching Programming Informatics in Education. Informatics in Education, 11(2), 271282.

Vopneruk, E.A., Zaykova, A.C. \& Ilichova, A.C. (2005). Interrelation of learning ability with the leading representative system. Psychological Bulletin of UrSU, 5, 47-60.

Wilson M. (2002). Six views of embodied cognition. Psychonomic Bulletin \& Review. 9(4), 625636.

Wilson, A.D., \& Golonka, S. (2013). Embodied Cognition is Not What you Think it is. Frontiers in Psychology, 4, 58. 